\title{
The Use of Sub-Seabed Transboundary Geological Formations for the Disposal of Carbon Dioxide
}

\author{
Nigel Bankes
}

\section{1 \\ Introduction}

This chapter examines the legal issues associated with the use of sub-seabed transboundary geological structures including saline aquifers for storage or disposal purposes. It focuses on carbon capture and storage (CCS), specifically the disposal element in the ccs chain.

The chapter proceeds as follows. Section 2 provides a brief discussion of cCs focusing on the disposal or storage part of the chain, as well as the injection of carbon dioxide $\left(\mathrm{CO}_{2}\right)$ as part of enhanced oil recovery (EOR) operations $\left(\mathrm{CO}_{2}\right)$ EOR). Section 3 deals with CCS and $\mathrm{CO}_{2} \mid$ EOR operations in transboundary formations, reviewing applicable international law requirements, such as the general duty to cooperate as well as the more explicit rules developed under the auspices of the London Dumping Convention $(\mathrm{LDC})^{1}$ and its Protocol (PLDC). ${ }^{2}$ It also examines the implications of Articles 74(3) and 83(3) of UN Law of the Sea Convention (UNCLOS) ${ }^{3}$ for the situations in which one party may be proposing to engage in ccs operations in an area of overlapping maritime entitlement claims in the absence of an agreed delimitation. Section 4 examines existing boundary delimitation agreements and joint development agreements in order to assess the extent to which they may apply to ccs and $\mathrm{CO}_{2} \mid$ EOR operations. Section 5 recognizes that straddling hydrocarbon deposits are frequently developed through unitization agreements between the

1 Convention on the Prevention of Marine Pollution by Dumping of Wastes and Other Matter, London, 13 November 1972.

2 Protocol to the Convention on the Prevention of Marine Pollution by Dumping of Wastes and Other Matter, London, 7 November 1996.

3 United Nations Convention on the Law of the Sea 1982, 1833 UNTS 3 and see generally British Institute of International and Comparative Law, Report on the Obligations of States under Articles 74(3) and 83(3) of UNCLOS in respect of Undelimited Maritime Areas, (2016) (hereafter BIICL report) available at <http://www.biicl.org/documents/1192_report_on_the_ obligations_of_states_under_articles_743_and_833_of_unclos_in_respect_of_undelimited_ maritime_areas.pdf?showdocument=1>. 
parties who hold the hydrocarbon exploitation rights from each state on either side of the maritime boundary. This section considers how this model might be applied to the situation where a shared formation is being used on one or both sides of the maritime boundary for ccs operations. Section 6 provides conclusions.

With its focus on the use of shared geological structures for disposal purposes, particularly for the disposal of $\mathrm{CO}_{2}$ the chapter does not review the general laws dealing with seabed disposal except to the extent that they specifically touch on the use of shared geological structures of the seabed. These general laws include provisions of UNCLOS, the LDC, the PLDC and the Convention for the Protection of the Marine Environment of the North-East Atlantic (OSPAR) ${ }^{4}$ and the Basel Convention. ${ }^{5}$ Both the PLDC and OSPAR have been amended to take account of $\mathrm{CO}_{2}$ disposal and both have developed regulatory guidance for CCS activities. There are a number of good accounts of how these instruments may apply (or not) to ccs activities in marine areas. ${ }^{6}$ Individual states have also adopted rules for CCS projects and, in the case of European Union (EU) Member States, these rules must comply with the terms of Directive 2009/21/ EC on the Geological Storage of Carbon Dioxide. ${ }^{7}$ Article 24 of the Directive specifically addresses the issue of transboundary storage and transboundary transport ${ }^{8}$ and provides that 'in such case the competent authorities of the

4 Convention for the Protection of the Marine Environment of the North-East Atlantic, Paris, 22 September 1992, in force 25 March 1998.

5 The Basel Convention on the Control of Transboundary Movements of Hazardous Waste and their Disposal, 22 March 1989, in force 1992.

6 Chiara Armeni, 'Legal Developments for Carbon Capture and Storage under International Regional Marine Legislation' in Ian Havercroft, Richard Macrory \& Richard B Stewart (eds) Carbon Capture and Storage: Emerging Legal and Regulatory Issues, (Hart, Oxford, 2011) 145-159; Tim Dixon, Sean McCoy and Ian Havercroft, 'Legal and Regulatory Developments on CCS' (2015), 40 International Journal of Greenhouse Gas Control 431; UNFCCC Secretariat, Transboundary carbon capture and storage project activities, Technical Paper, 1 November 2012 UNFCCC/TP2012/9, (hereafter UNFCCC, Transboundary CCS Technical Paper) available at $<$ http://unfccc.int/resource/docs/2012/tp/og.pdf >; Carbon Sequestration Leadership Forum, Technical Group, 'Final Report from Task Force on Technical Barriers and R \& D Opportunities for Offshore, Sub-Seabed Geologic Storage of $\mathrm{CO}_{2}$, CSLF-T-2015-06, 20 October 2015 (hereafter CSLF Offshore Geologic Storage) available at <http://www.cslforum.org/publica tions/documents/riyadh2015/tg_OffshoreSubSeabedStorageTaskForceFinalReport-Riyadh 1115.pdf>

7 Directive 2009/31/EC of the European Parliament and of the Council of 23 April 2009 on the geological storage pf carbon dioxide, as amended.

8 Article 2, ibid, prohibits the storage of $\mathrm{CO}_{2}$ in a storage site with a storage complex extending beyond the territories, exclusive economic zones and continental shelves of Member States. 
Member States concerned shall jointly meet the requirements of this Directive and of other relevant Community legislation. ${ }^{9}$

Neither does this chapter deal with the much-discussed question of the eligibility of ccs projects for crediting under the terms of the Clean Development Mechanism (CDM) of the Kyoto Protoco ${ }^{10}$ of the UN Framework Convention on Climate Change (UNFCCC) ${ }^{11}$ other than to note that when the Meeting of the Parties ultimately decided to make ccs projects CDM eligible it did so subject to exceptions for project activities which involve the transport of $\mathrm{CO}_{2}$ from one country to another and which involve geological storage sites located in more than one country. ${ }^{12}$

\section{$2 \quad$ Carbon Capture and Storage and $\mathrm{CO}_{2} \mid \mathrm{EOR}$}

This Section discusses first ccs generally $(2.1)$ and then the injection of $\mathrm{CO}_{2}$ for EOR purposes (2.2). It concludes with some comments on the transboundary implications of CCS and $\mathrm{CO}_{2} \mid$ EOR operations (2.3).

9 The recent review of the Directive, Report on Review of Directive 2009/31/EC, СOM (2015) 576 final, Annex 2, 18 November 2015 reported (at 5) there was no practical experience to date with transboundary issues but (at 7) that parties should consider cooperation to reduce costs and that the Connecting Europe Facility might "play a role in supporting cross-border transport networks and regional cooperation in this area." For discussion of the coordination issues that might arise see David Langlet, 'Transboundary Dimensions of CCS: EU Law Problems and Prospects' (2014) CCLR 196 at 206.

10 Kyoto Protocol to the UN Framework Convention on Climate Change, Kyoto, 11 December 1997.

11 UN Framework Convention on Climate Change, New York, 9 May 1992.

12 Decision 10/CMP.7, paragraph 6, http://unfccc.int/resource/docs/2011/cmp7/eng/10a 02.pdf. Further consideration of transboundary projects were deferred until SBSTA 45 and CMP 12 in Marrakech, November 2016 at which point the CMP accepted SBSTA's recommendation to the effect that since no party had applied for registration of a cCs project as a CDM activity that it was appropriate "to conclude the consideration of the eligibility" of transboundary projects: FCCC/SBSTA/2016/L.19/Add.1. See generally Tim Dixon, Gregory Leaman, Paul Zakhour and Luke Warren, "CCS Projects as Kyoto Protocol CDM activities" (2013), 37 Energy Procedia 7596. A more specific article is Viviane Romeiro and Virginia Parente, "Carbon Capture and Storage and the UNFCCC: Recommendations to Address Trans-Boundary Issues" (2012), 3 Low Carbon Economy 130. Despite its title this paper is principally concerned with transboundary transportation of $\mathrm{CO}_{2}$ for injection purposes and related accounting issues. 


\subsection{Carbon Capture and Storage - Generally}

CCS is a recognized technology for mitigating greenhouse gas (GHG) emissions, and, in particular $\mathrm{CO}_{2}{ }^{13} \mathrm{CCS}$ involves the capture of $\mathrm{CO}_{2}$ at large final emitters (LFEs), ${ }^{14}$ the compression and transportation of the $\mathrm{CO}_{2}$ and its injection under pressure into suitable geological formations..$^{15}$ The main targets are depleted oil and gas reservoirs and saline aquifers; the latter are much more significant in terms of volume. Two important examples of this are the Sleipner and Snøhvit projects on the Norwegian continental shelf. Sleipner commenced operations in 1996 and Snøhvit in $2008 .{ }^{16}$ Both inject $\mathrm{CO}_{2}$ into saline formations.

Injection sites may be onshore or offshore (as above). ${ }^{17}$ There are positive and negative aspects associated with selecting an offshore disposal site. Positive aspects include the following: sediments of continental shelves frequently contain large volumes of high quality storage; in many cases prior oil and gas exploration on shelves provides a good geological understanding of the offshore; there is typically a single owner (the state) and no severance of surface and mineral titles; there is minimal conflict with freshwater aquifers (a major potential concern with onshore sites); the absence of resident populations and communities; there is frequently an existing pipeline and production|injection infrastructure; likely fewer wells offshore than onshore to serve as possible pathways to surface; it may be easier and cheaper to apply monitoring techniques and seismic imaging offshore. ${ }^{18}$ In addition, it may simply be the case that a state has no suitable onshore sites. The principal disadvantages of offshore sites are the elevated costs and risks of offshore

13 A particularly useful policy oriented study is IEAGHG, Interaction of $\mathrm{CO}_{2}$ Storage with Subsurface Resources, Report 2013-08, April 2013, (hereafter IEAGHG Interaction Report). The report is available here http://ieaghg.org/docs/General_Docs/Reports/2013-08.pdf.

14 The LFEs at which capture may occur may include power plants (coal or natural gas) and a range of industrial facilities including cement operations and a variety of hydrocarbon processing facilities.

15 In some cases natural gas reserves (methane, $\mathrm{CH}_{4}$ ) may be contaminated with a significant percentage of $\mathrm{CO}_{2}$ requiring processing in the field to produce pipeline quality gas. The separated $\mathrm{CO}_{2}$ may then be reinjected.

16 The Sleipner project is located $240 \mathrm{~km}$ west of Stavanger. Processing and injection occur at the production site. The Snøhvit project involves production from three separate fields in the Barents Sea north of Norway northern coast. The gas is piped to shore to a processing and LNG facility. The $\mathrm{CO}_{2}$ is separated and piped back to the field for injection. See: CSLF Offshore Geologic Storage (n 6) at 8-9.

17 In one case, the Tomakomai Demonstration Project (Japan), the drill site is on land but the injection wells are highly deviated and the targeted formations are between 3 and 4 $\mathrm{km}$ offshore. See CSLF Offshore Geologic Storage (n 6) at 11.

This section relies on CSLF Offshore Geologic Storage (n 6) at $2 \& 5$. 
operations as well as concerns for the marine environment. ${ }^{19} \mathrm{~A}$ recent report (2013) by the International Energy Agency concluded that $\mathrm{CO}_{2}$ storage is not likely to take place in the near future at onshore locations in the five countries surrounding the North Sea and that the North Sea is a much more promising option both for those countries 'and indeed for many other nearby European countries.' $^{20}$

Injection sites should be carefully characterized and located so as to ensure adequate and efficient storage capacity ${ }^{21}$ as well as geological containment with appropriate trapping mechanisms. ${ }^{22}$ Possible pathways to the surface (or sources of potable water) should be assessed, including natural fault lines and existing wells. While disposal into a depleted oil and gas reservoir involves injection into an underpressured formation (because of past production) injection into a saline formation will occur at natural formation pressure. Thus, the $\mathrm{CO}_{2}$ will need to be injected 'at pressure higher than the natural formation pressures to be able to displace resident brines.'23 Upon injection the

19 Ibid at 6.

20 IEAGHG Interaction Report, (n 13) at 37-38. There have been a number of regional scale European studies of offshore storage options. These studies include One North Sea, A study into North Sea $\mathrm{CO}_{2}$ cross-border transport and storage. Final Main report for the Norwegian Ministry of Petroleum and Energy and the UK Foreign and Commonwealth Office on behalf of the North Sea Basin Task Force (authors: Elements Energy Limited) 2010 available at <http://www.ccsassociation.org/docs/2010/OneNorthSea.pdf> Chapter 6 deals with legal and regulatory issues; Carbon Capture and Storage in the Skagerrak/Kattegat Region, Final Report, February 2102, available at <http://interreg-oks.eu/webdav/files/ gamla-projektbanken/se/Material/Files/Kattegat/Skagerrak/Dokumenter+projektbank/ CCS\%2ofinal\%2oreport.pdf $>$ the report contains a chapter on 'legal issues concerning ccs' authored by David Langlet; ccs in the Baltic Region - Bastor 2, Final Summary Report, Elforsk Report 14:50, 30 September 2014 available at <http://www.elforsk.se/ Rapporter/?rid=14_50_> This report also contains a chapter on 'legal aspects' also authored by Langlet. A more detailed report Nils Rydberg and David Langlet, Work Package 4 LegalandFiscal Aspects(nd) is availableherehttps://www.globalccsinstitute.com/publications/ccs-baltic-sea-region-bastor-2-work-package-4-legal-and-fiscal-aspects Most of the legal analysis in these reports is concerned with the EU Directive and the PLDC. There is more limited consideration of the problems posed by transboundary storage complexes.

21 Stefan Bachu, 'Review of $\mathrm{CO}_{2}$ storage efficiency in deep saline aquifers' (2015), 40 International Journal of Greenhouse Gas Control 188. 'Storage efficiency' refers to the fact that not all available pore space will be accessed by $\mathrm{CO}_{2}$ in the same way as not all estimated hydrocarbon reserves will be producible.

22 The literature refers to six trapping mechanisms which may operate cumulatively and over different time scales: (1) structural and stratigraphic trapping, (2) hydrodynamic traps $\left(\mathrm{CO}_{2}\right.$ entrained in groundwater, (3) residual gas trapping, (4) solubility trapping, (5) mineral trapping, (6) adsorption trapping. IEAGHG Interaction Report (n 13) at 7 .

23 Jens T Birkholzer, Curtis M. Oldenberg and Quanlin Zhou, ' $\mathrm{CO}_{2}$ migration and pressure evolution in deep saline aquifers' (2015), 40 International Journal of Greenhouse Gas Control 203, 209. 
$\mathrm{CO}_{2}$ will migrate within the target formation as a plume of $\mathrm{CO}_{2}$. The $\mathrm{CO}_{2}$ will be buoyant relative to the brine in the reservoir and will thus rise and spread laterally when trapped under cap-rock formations. ${ }^{24}$ Injection will also elevate pressure conditions within the reservoir. The pressure effect of injection will initially be localized at the injection site but the resulting pressure front will extend beyond the actual $\mathrm{CO}_{2}$ plume (in some cases as far as $100 \mathrm{~km}^{25}$ ) and slowly dissipate throughout the target formation. Once injection comes to an end, the $\mathrm{CO}_{2}$ plume may continue to migrate within the target formation moving upwards and laterally (because of the buoyancy of the plume) ${ }^{26}$ Migration will continue at a slow rate for centuries.

It is important to keep in mind the industrial scale of operations that will be required if CCS is to make a significant contribution to the mitigation of GHG emissions. Birkholzer et al provide a useful example noting that a $1000 \mathrm{MW}$ power plant (enough electricity for one million people) will provide enough $\mathrm{CO}_{2}$ over the life of the plant to create a subsurface $\mathrm{CO}_{2}$ plume with linear dimensions of $10 \mathrm{~km}$ with pressure plume extending over $100 \mathrm{~km} .{ }^{27}$ As a result: 'In a future world with ccs being a fully employed technology, sedimentary basins with interconnected reservoirs might host multiple storage sites in which case pressure interference could be expected between individual projects. $^{28}$

The precise implications of the pressure changes in a formation as a result of injection will depend on the type of formation or 'storage system'29 Open systems are likely the most desirable for large scale storage since they provide opportunities for pressure dissipation. Elevated pressures in a closed system or at the point of injection may impair cap rock integrity. It may be necessary

\footnotetext{
24 id, 206.

25 IEAGHG Interaction Report (n 13) at 67.

26 Bachu (n 21) at 198.

27 Birkholzer et al (n 23) at 204.

28 Bachu (n 21) at 197 and 198.

29 The literature distinguishes different types of storage system: closed systems (characterized by a formation surrounded laterally by impervious boundaries and vertically by sealing formations) and open systems where the large scale storage formation is overlain by a series of sealing formations but where the lateral boundaries are so far away that they will be unaffected by pressure changes. See Quanlin Zhou and Jens Birkholzer, 'On scale and magnitude of pressure build-up induced by large-scale geologic storage of $\mathrm{CO}_{2}{ }^{\prime}(2011)$, 11(1) Greenhous Gases Science and Technology 11, 12. The authors actually offer three categories - the middle category is a semi-closed system characterized by semi-pervious sealing units. See also Bachu (n 21) at 189 \& 191.
} 
for projects to adopt pressure management techniques to respond to this problem. ${ }^{30}$

The principal environmental concerns associated with $\mathrm{CO}_{2}$ storage in saline aquifers, in addition to leakage to surface, include the migration of displaced brines causing potable groundwater contamination, not simply as a result of elevated salinity but also because brines may have elevated concentrations of heavy metals and natural radioactive materials. ${ }^{31}$ This is far less likely to be a concern for ocean storage sites because there will generally be no potable groundwater sources that are at risk of contamination.

In addition it may also be necessary to assess resource interactions i.e. the competing uses of available geological storage space and the implications of one resource use for others. These implications may be positive or negative. ${ }^{32}$

\section{$2.2 \quad \mathrm{CO}_{2}$ Storage and Enhanced Oil Recovery}

Enhanced oil recovery using carbon dioxide $\left(\mathrm{CO}_{2} \mid \mathrm{EOR}\right)^{33}$ is a tertiary recovery technique for enhancing recovery of petroleum from some reservoir types. ${ }^{34}$ Primary production (using the original pressure conditions in the reservoir) may result in the recovery of between 10 and $20 \%$ of the original oil in place in the reservoir (OOIP)..$^{35}$ Waterflooding operations and other secondary recovery techniques may double the recovery rate. $\mathrm{CO}_{2} \mid$ EOR operations may allow the recovery of an incremental $5^{-15} \%$ of the ooIP and in some cases as much as an additional $25-40 \% . \mathrm{CO}_{2} \mid$ EOR operations involve the injection of liquid

30 Bachu (n 21) at 199 and IEAGHG Interaction Report (n 13) at 47-52 discussing the Gorgon Project, Western Australia, which contemplates using, in addition to nine $\mathrm{CO}_{2}$ injection wells, a pressure management scheme using four production wells for pressure relief and two injection wells for the produced water.

31 Birkholzer et al (n 23) 211.

32 The IEAGHG Interaction Report (n 13) esp at 17-69 assesses possible subsurface resource interactions between cCs projects and a variety of other uses.

33 This section draws on a number of sources including the Report Prepared for the Carbon Sequestration Leader Forum (CSLF) Technical Group by the CSLF Task Force on the Technical Challenges in the Transition from $\mathrm{CO}_{2}$-EOR to CCS, September 2013, (CSLF, $\mathrm{CO}_{2}$ |EOR Technical Report) http://www.cslforum.org/publica tions/documents/CO2-EORtoCCS_FinalReport.pdf; Philip M. Marston, Patricia A. Moore and J. Greg Schnacke, "Carbon Dioxide Infrastructure: Pipeline Transport Issues and Regulatory Concerns - Past, Present and Future" (2015), $5^{2}$ Rocky Mountain Mineral Law Foundation Journal 275-313 esp at 278-286, Nigel Bankes and Elizabeth Brennan, "Enhanced oil recovery and the geological sequestration of carbon dioxide", 2013, a paper prepared for Natural Resources Canada, http://www.law.ucalgary.ca/files/law/final_june7 _enhanced-oil-recovery-and-the-geological-sequestration-of-carbon-dioxide.pdf.

34 Not all fields are suitable for $\mathrm{CO}_{2} \backslash$ EOR operations or even for $\mathrm{CO}_{2}$ storage in a depleted reservoir. For an accessible account of relevant considerations see IEAGHG Interaction Report (n 13) at 12.

35 Marston et al, (n 33) 279. 
or supercritical $\mathrm{CO}_{2}$ into the producing formation where the $\mathrm{CO}_{2}$ interacts with the oil remaining in the pores of the formation. Marston et al describe the process as follows: ${ }^{36}$

... the dense-phase $\mathrm{CO}_{2}$ becomes miscible with the oil (i.e. the two substances will flow together as if they were a single fluid). In the process, the oil droplets swell and the surface tension that held the oil droplets attached to the pore surfaces is reduced. This allows the oil to become mobile.

The combined fluids (oil, $\mathrm{CO}_{2}$ and brine) flow towards the low pressure point of the producing well. As the substances are produced any entrained $\mathrm{CO}_{2}$ returns to the gaseous phase. The fluids and gases are separated and collected at the surface. Captured $\mathrm{CO}_{2}$ is dehydrated, pressurized and re-injected. The operator has an incentive to engage in re-capture because the costs of recapture are lower than the costs of acquiring supplementary sources of $\mathrm{CO}_{2}$ with which to continue the EOR operation. Not all of the $\mathrm{CO}_{2}$ injected will be produced with the oil, some will remain permanently contained within the reservoir. Industry experience with EOR projects suggests that up to $90-95 \%$ of purchased $\mathrm{CO}_{2}$ will eventually become 'incidentally trapped' (i.e. stored) within the reservoir over the life of the project. ${ }^{37}$

While $\mathrm{CO}_{2} \mid$ EOR operations may be relatively small scale, they offer some significant advantages when compared with ccs. The most important of which is that the incremental oil recovery provides a source of revenue to offset the expenses involved in capturing the $\mathrm{CO}_{2} \cdot{ }^{38}$

There may also be other non-carbon advantages for $\mathrm{CO}_{2} \backslash \mathrm{EOR}$ operations. For example, the use of $\mathrm{CO}_{2} \mid$ EOR in the North Sea should extend the producing lives of North Sea reservoirs and the basin as a whole thereby reducing the need for imports and maintaining employment. ${ }^{39}$

$36 \quad$ Ibid 281. Emphasis in original, references omitted.

37 Ibid 283 referring to various sources including CSLF, $\mathrm{CO}_{2}$ |EOR Technical Report (n 33) and Global cCs Institute, "The Global Status of CCS: 2012" at 147.

38 The CSLF Technical Group report summarizes the advantages as follows:".... 1) it enables cCs technology improvement and cost reduction; 2) it improves the business case for ccs demonstration and early movers; 3 ) it supports the development of $\mathrm{CO}_{2}$ transportation networks; 4) it may provide significant $\mathrm{CO}_{2}$ storage capacity in the short-to-medium-term, particularly if residual oil zones (ROz) are produced; 5) it enables knowledge transfer, bridging the experience gap and building and sustaining a skilled CCS workforce; and 6) it helps gaining public and policy-makers acceptance". See CSLF, $\mathrm{CO}_{2} \backslash$ EOR Technical Report (n 13), 1 \& 58.

39 sccs, $\mathrm{CO}_{2}$ Storage and Enhanced Oil Recovery in the North Sea: Securing a Low Carbon Future for the $U K,(2015)$ at 2. Available at <http://www.sccs.org.uk/images/expertise/ reports/co2-eor-jip/SCCS-CO2-EOR-JIP-Report-SUMMARY.pdf> 
Despite those prospects, there are very few offshore $\mathrm{CO}_{2} \mid$ EOR projects due to the limited availability of $\mathrm{CO}_{2}$ and the cost of converting existing infrastructure. ${ }^{40}$

\subsection{Transboundary Implications of Saline Disposal and $\mathrm{CO}_{2} \mid \mathrm{EOR}$ Projects}

It is apparent that the geographical implications of a saline disposal project will be more widespread and cover much larger areas than those associated with $\mathrm{CO}_{2} \mid$ EOR projects. This is because conventional oil and gas reservoirs are always closed systems ${ }^{41}$ and the individual reservoirs will be much smaller than the regional scale, open geological formations that will likely be the target of saline disposal projects. A saline disposal project may raise transboundary concerns in one of two ways. First and most directly, the $\mathrm{CO}_{2}$ plume itself may migrate across the boundary. Second, and more indirectly, the pressure front associated with injection into a formation on one side of the boundary may extend across the boundary even through the plume itself may never do so. Increased formation pressure may make these adjacent areas less useful for other ccs operations since pressure conditions will affect the injectivity of the formation. Brine migration induced as a result of the pressurization may be of concern for groundwater resources if present. ccs projects may have implications for other adjacent resource activities as noted above. ${ }^{42}$

$\mathrm{CO}_{2} \mid$ EOR projects on the other hand are unlikely to pose new transboundary problems for two reasons. First, since EOR operations occur in contained reservoirs that are well characterized there are less likely to be regional scale pressure implications. ${ }^{43}$ Thus, unless the reservoir itself crosses the boundary there are unlikely to be transboundary effects. Second, if the reservoir does cross the boundary it will already be subject to some form of agreement whether a project specific treaty and unitization agreement or some form of framework or unitization agreement. ${ }^{44}$ At most the question becomes one of asking how those arrangements might accommodate $\mathrm{CO}_{2} \mid$ EOR operations.

40 CSLF Sub-Seabed Geologic Storage (n 6) at 14. There is only one significant offshore $\mathrm{CO}_{2} \backslash$ EOR project and that is Lula Project, Brazil, id at 11. There is also one offshore $\mathrm{CO}_{2}$ enhanced gas recovery (EGER) project. This is the experimental K12-B project in the Dutch sector of the North Sea about $150 \mathrm{~km}$ northwest of Amsterdam. For details see IEAG HG, Review of Offshore Monitoring for CCS Projects, 2015/02, July 2015 at 22-23, available at <http://www.ieaghg.org/docs/General_Docs/Reports/2015-02.pdf> .

41 Non-conventional hydrocarbon reserves (e.g. shale oil and gas) however represent accumulations of hydrocarbons that have not migrated into structural traps.

42 See also UnfCCC, Transboundary ccs Technical paper (n 6) at para 110.

43 There may be some exceptions if different pools are connected to a regional aquifer system.

44 This question is discussed further below in Section 4. 


\section{The Law Governing $\mathrm{CCs}$ Operations and $\mathrm{CO}_{2} \mid$ EOR Operations in Transboundary Formations}

The present section considers the applicable law specifically with respect to CCS operations and $\mathrm{CO}_{2} \mid$ EOR operations in transboundary formations. While some may express doubts as "to the correct ground for exercising coastal state jurisdiction" with respect to cCs operations ${ }^{45}$ there surely cannot be any doubt that a coastal state has exclusive jurisdiction to authorize CCS and $\mathrm{CO}_{2} \mid \mathrm{EOR}$ operations within its territorial sea, ${ }^{46}$ exclusive economic zone ${ }^{47}$ and the continental shelf ${ }^{48}$ including any extended continental shelf beyond $200 \mathrm{~nm} .{ }^{49}$

The section summarizing the general rules pertaining to the duty to cooperate under UNCLOS as well as the more specific rules pertaining to shared resources including the work of the International Law Commission (ILC) in relation to shared groundwater resources (3.1). Section 3.2 examines the treatment of sub-seabed disposal of $\mathrm{CO}_{2}$ in shared formations under the LDC and its Protocol. The section ends by reviewing the implications of Articles 74(3) and 83(3) of UNCLOS for the situations in which one party may be proposing to engage in CCS operations in an area of overlapping maritime entitlement claims in the absence of an agreed delimitation (3.3).

\subsection{The General Duty to Co-operate}

International law recognizes a general obligation to cooperate in relation to the use of shared resources. ${ }^{50}$ Shared geological structures which can be used for storage or disposal purposes are examples of shared resources.

45 David Langlet, 'Transboundary Dimensions of ccs: EU Law Problems and Prospects' (2014) CCLR 196 at 201 (emphasis added). As Langlet concedes all seabed CCS operations require drilling.

46 UNCLOS Article 2 ( $\mathrm{n}_{3}$ ) the sovereignty of a coastal State extends to the territorial sea.

47 UNCLOS Article 56 , sovereign rights for inter alia exploring, exploiting and managing the natural resources of the seabed and its subsoil, subject to "due regard" obligations with respect to the rights and duties of other States. UNCLOs Article 60 accords the coastal state the exclusive right to construct and exercise jurisdiction over installations and structures for the purposes of Article 56 .

48 UNCLOS Article 77 extends to the coastal state the exclusive sovereign rights to explore and exploit the natural resources of the continental shelf which comprise the sea-bed and subsoil. UNCLOS Article 81 confirms that the coastal state has the exclusive right to authorize and regulate drilling on the shelf and Article 80 makes it clear that Article 60 applies mutatis mutandis to installations and structures on the shelf.

49 UNCLOS Article 76.

50 David M. Ong, 'Joint Development of Common Offshore Oil and Gas Deposits: "Mere" Sate Practice of Customary International Law' (1999), 93 AJIL 771 esp at 780-781. Ong refers to a number of sources including Article 3 of the Charter of Economic Rights and Duties of States, GARes 3281 (xxIX), UN GAOR, 29th Sess., Supp. No. 30, UN Doc. A/9030 (1974) 
The ILC has endeavored to codify the law pertaining to a number of shared resources, specifically the non-navigational uses of international watercourses $^{51}$ and shared aquifers. The Commission's Draft articles on the Law of Transboundary Aquifers, with commentaries were adopted on second reading in 2008 (hereafter Draft Articles). ${ }^{52}$ While these articles are principally concerned with the use of aquifers for potable drinking water a number of references in the articles and the commentary suggest that the ILC contemplated that the articles should also speak to the use of aquifers for disposal purposes including for geological sequestration of $\mathrm{CO}_{2}{ }^{53}$ However, the commentary to the Draft Articles also makes it clear that the Commission concluded that the Articles should not apply to aquifers underlying the continental shelf on the grounds that 'Submarine geological formations under the continental shelf do not hold freshwater and accordingly such formations and water therein fall outside the scope of the draft articles. 54 While the Commission seems inconsistent with respect to the applicability of the articles to the use of

and the Draft Principles of Conduct in the Field of the Environment for the Guidance of States in the Conservation and Harmonious Utilization of Natural Resources Shared by Two or More States, adopted by the United Nations Environment Programme in 1978, available at $<$ http://www.unep.org/training/programmes/Instructor\%2oVersion/Part_2/ Activities/Interest_Groups/Decision-Making/Supplemental/Enviro_Law_Guidelines_ Principles_rev2.pdf $>$. See also Tara Davenport, 'The exploration and exploitation of hydrocarbon resources in areas of overlapping claims' in in S. Jayakumar, Tommy Koh and Robert Beckman (eds), The South China Sea Disputes and the Law of the Sea, Edward Elgar, Cheltenham, 2014, 93-113 at 107.

The ILC's work on this topic resulted in the adoption of the UN Convention on the Non-Navigational Uses of International Watercourses, 21 May 1997, <http://legal.un.org/ ilc/texts/instruments/english/conventions/8_3_1997.pdf>

International Law Commission, Draft articles on the Law of Transboundary Aquifers, with commentaries, adopted at the ILC 6oth Session, (2008) online: <http://untreaty .un.org/ilc/texts/instruments/english/commentaries/8_5_2008.pdf> (ILC Draft Articles).

53 See e.g. the definition of 'utilization of transboundary aquifers or aquifer systems' (Article 2(e) ibid) which refers to 'extraction of water, heat and minerals, and storage and disposal of any substance'; furthermore the commentary to that definition notes that 'Extraction of freshwater is of course the main utilization of aquifers'. Other kinds of utilization, however exceptional and peripheral, should not be ignored. 'Utilization' is defined in a non-exhaustive manner to include not only extraction of water but also extraction of heat for thermo-energy, extraction of minerals that may be found in aquifers, as well as storage or disposal of waste, such a new experimental technique to utilize an aquifer for carbon dioxide sequestration." There is a further reference to geological sequestration in the commentary to article 4 dealing with the principle of equitable and reasonable utilization: 'an aquifer may also be used for disposal, in particular through a new experimental technique to utilize aquifers for carbon dioxide sequestration. This use is peripheral to the present draft articles.' It is an open question whether the balance of the text of the articles was really drafted with ccs and other disposal operations in mind.

Paragraph (2) of the commentary to Article 2. 
aquifers for sequestration or disposal purposes the principles underlying these articles should still inform how we might think about the duty to cooperate in the context of shared geological formations in marine areas. ${ }^{55}$

The duties associated with the general obligation to cooperate ${ }^{56}$ include both procedural and substantive duties. Procedural duties include the duty to exchange information about the resource, ${ }^{57}$ the duty to notify as to proposed uses of the shared resource which may affect other parties, ${ }^{58}$ the duty to conduct an environmental assessment to the extent that transboundary impacts are anticipated, ${ }^{59}$ the duty to engage in consultations as to any concerns that are identified and if necessary to negotiate (or engage in other peaceful means of dispute resolution) to resolve any outstanding issues. ${ }^{60}$ There may also be a duty to monitor the use and status of the shared resource and to share the resulting information. ${ }^{61}$ The substantive duties include a duty of equitable and reasonable utilization of the shared resource, ${ }^{62}$ the duty to protect the environment, ${ }^{63}$ and the duty not to cause significant harm to the shared resource or the interests of other states in that resource. ${ }^{64}$ What amounts to harm, and indeed to significant harm, must be contextualized and to some extent may depend upon the uses that others may be making of that resource. Thus, disposal of $\mathrm{CO}_{2}$ into an aquifer may be a reasonable use of that aquifer if it is saline; it is likely not a reasonable use if the aquifer contains potable groundwater and certainly not if the aquifer is being used as a potable water source by another aquifer state.

The duty to cooperate with respect to shared resources may also result in the aquifer states agreeing to create appropriate institutions. Such institutions have proven to be particularly important in relation to international watercourses. The draft articles on aquifers refer inter alia, to joint mechanisms of

55 See also UnfCcc, Transboundary ccs Technical Paper (n 6) at para 63 noting that parties 'may wish to consider the cooperative and regulatory approaches adopted in relation to the management of water resources and oil and gas reserves' and see also at para 66 a similar comment specifically with respect to the ILC draft articles.

$5^{6} \quad$ ILC Draft Articles (n $5^{2}$ ), Article 7, General obligation to cooperate.

57 Ibid Article 8, Regular exchange of data and information.

58 Ibid Article 15, Planned activities.

59 Ibid Article 15(2) and paragraph (4) of the commentary.

6o Ibid Article 15(3).

61 Ibid Article 15, Monitoring.

62 Ibid Articles 4 \& 5 .

63 Ibid Article 10, 'Protection and preservation of ecosystems', Article 12, 'Prevention, reduction and control of pollution'

64 Ibid Article 5 . 
cooperation, appropriate bilateral and regional agreements, joint monitoring activities, and a joint management mechanism. ${ }^{65}$

In addition to the general duties to cooperate with respect to shared resources as well as the more specific rules in relation to transboundary aquifers, UNCLOS also contains a number of provisions enjoining the parties to cooperate including the duty to cooperate in relation to the conservation and management of living resources, the duty to co-operate with respect to enclosed and semi-enclosed seas and the duty to cooperate with respect to the protection of the marine environment. ${ }^{66}$ There are rather more specific provisions requiring the relevant parties to pursue provisional arrangements in areas of overlapping maritime entitlements. ${ }^{67}$ These provisions are the subject of more detailed examination below in section 3.3.

\subsection{The Treatment of Sub-Seabed Disposal of $\mathrm{CO}_{2}$ in Shared Formations in the Work of Protocol to the London Dumping Convention}

The one treaty forum that has addressed storage in shared geological structures in marine areas is the Protocol to the London Dumping Convention (PLDC) ${ }^{68}$ It will be recalled that the parties to the PLDC agreed to amend that instrument to permit geological sequestration of pure streams of $\mathrm{CO}_{2}{ }^{69}$ The parties also agreed that the injection of $\mathrm{CO}_{2}$ for enhanced oil recovery purposes does not engage the Protocol. ${ }^{70}$ That amendment and the understanding with respect to $\mathrm{CO}_{2}$ for EOR purposes did not resolve all issues relating to the potential use of the seabed for geological sequestration because Article 6 of the PLDC prohibits the export of wastes. The Parties identified two potential implications of this prohibition for geological sequestration of $\mathrm{CO}_{2}$ : export and migration (or 'migration-as-export'). 'Export' refers to the export of $\mathrm{CO}_{2}$ from one country for disposal in the jurisdiction of another country. It was agreed that this activity was subject to the prohibition of Article 6, that the problem could not be resolved by way of an agreed interpretation, and that it could only be resolved by means of an amendment. An amendment to create an exception for the

65 Draft Articles, Articles 7, 9, 13, \& 14.

66 UnCLOS (n 3) Articles 61(2), 64, 65, 66, 117, 118, 123, 194, \& 197-201. Ong (n 5o) at 781-785, Davenport (n 50$)$ at 107.

$67 \quad$ UnCLOS (n 3) Articles $74 \& 83$.

68 PLDC (n 2).

69 LC 28/15.6 adopted November 2006 entered into force 10 February 2007; discussed in Dixon et al (n 12) at $433-436$.

70 See International Maritime Organization (IMO) webpage, Carbon Capture and Sequestration <http://www.imo.org/en/OurWork/Environment/LCLP/EmergingIssues/ CCS/Pages/default.aspx> 
export of $\mathrm{CO}_{2}$ for geological sequestration was adopted in 2009 but is still a long way from entering into force. ${ }^{71}$

The migration-as-export concern is particularly relevant for this chapter since it concerns the scenario in which $\mathrm{CO}_{2}$ is injected into a shared geological structure in State $\mathrm{A}$ and the $\mathrm{CO}_{2}$ plume migrates (either intentionally or unintentionally) from State A to State B (or to an area beyond national jurisdiction). The Parties concluded that such a migration does not constitute an export within the meaning of Article 6 (and adopted a resolution to that effect). ${ }^{72}$ It is therefore a form of disposal which is permitted under the newly adopted amendment. However, the parties considered that it required special consideration under the terms of the Specific Guidelines for the Assessment of Carbon Dioxide for Disposal into Sub-seabed Geological Formations. The Guidelines were first adopted in 2007; the amended version which addresses the migration scenario was adopted in November 2012. ${ }^{73}$ The Specific Guidelines (2012) address geological waste disposal of $\mathrm{CO}_{2}$ generally but also contain a number of more specific provisions dealing with disposal into geological formations where there is potential for transboundary movement of injected $\mathrm{CO}_{2}$. The general provisions address such matters as waste prevention audits, consideration of waste management options, the chemical and physical properties of the waste stream (i.e. proper characterization of the waste stream), an action list (a screening tool to determine whether a material is considered acceptable for dumping), site selection and characterization, assessment of potential effects (a risk assessment and an impact hypothesis), monitoring and risk management, and permit and permit conditions. ${ }^{74}$

The main provision dealing with disposal into geological formations where there is potential for transboundary movement of injected $\mathrm{CO}_{2}$ is an overarching provision which precedes the general provisions outlined above and provides as follows: ${ }^{75}$

7131 August 2018 only 5 parties had ratified the amendment: Norway, Netherlands, UK, Iran and Finland, LC 40/2, 31 August 2018.

72 Resolution LP.3(4), 30 October 2009, Recital 12.

73 Adopted 2 November 2012, LC 34/15, annex 8 (Specific Guidelines, 2012).

74 For more detailed discussion see Dixon et al (n 12) at 434. See also IEAGHG, Review of Project Permits under the London Protocol - An Assessment of the Proposed P18-4 $\mathrm{CO}_{2}$ Storage Site, Report: 2016/TR4, May 2016. The project involves injection and storage into the $\mathrm{P} 18-4$ field which is a near-depleted natural gas field located approximately $20 \mathrm{~km}$ off the Dutch Coast. The report involves an analysis of the Netherlands permitting exercise to test compliance with the Specific Guidelines. It does not contain an assessment of potential transboundary issues presumably because the storage complex was a confined rather than an open complex.

Specific Guidelines (n 73) para 1.10 - bolded letters and numbers added. 
[A] In the case of [1] transboundary sub-seabed geological formations that could be used by more than one country or [2] where sub-seabed geological formations are located in areas where there is the potential for transboundary movement of $\mathrm{CO}_{2}$ streams after injection [3] the Contracting Party where the injection occurs should be responsible for the implementation of these Specific Guidelines. [B] Consent should be sought for the use of the sub-seabed geological formation from all countries with jurisdiction over this sub-seabed geological formation, without prejudice to international law including as reflected in the relevant provisions of UnCLOS. [C] The Contracting Party where the injection occurs should cooperate with other relevant Contracting Parties, other States and other relevant entities, to ensure adequate sharing of information as needed and in accordance with international law, including by way of arrangement or agreement to ensure that these Specific Guidelines are implemented effectively.

There are a number of key ideas embedded in this paragraph.

First, sentence $[\mathrm{A}]$ serves to both identify the circumstances under which the clause shall apply but also to allocate compliance responsibility. Thus, the Guidelines apply where, $[\mathrm{Al}]$ a sub-seabed geological formation could be used by more than one country, or [A2] there is a formation which is located in an area where there is potential for transboundary migration post-injection. This first sentence establishes low alternative thresholds for its applicability. The first alternative, threshold [A1], is satisfied by the mere existence of a geological formation that could be used by more than one country. The second alternative, threshold [A2], is satisfied by the potential for transboundary migration. The allocation of compliance responsibility is dealt with in the last part of the first sentence [A3] which resolves that it is the State where the injection occurs that is responsible for the implementation of the Guidelines.

Second, sentence [B] establishes the threshold for proceeding. This requires that consent should be sought from all countries with jurisdiction over the shared sub-seabed geological formation. This requirement is said to be without prejudice to international law generally and UNCLOS specifically. The consent requirement is broadly framed. It is not confined to seeking to obtain consent from states to which the plume may migrate, or states that may suffer a (significant) adverse effect from use of the shared formation; it extends to any state with whom the formation may be shared. The consent is framed in the passive voice. It does not specify that the consent is to be obtained by the Contracting Party (rather than, say, the operator of the project) but the section 
as a whole is very state-oriented and thus it seems reasonable to think that consent should be obtained at the state to state level. The clause does not prescribe the form that the consent must take, such as whether it might take the form of a treaty or an agreement between the respective regulatory authorities of the parties, or an exchange of diplomatic notes. It is difficult to divine the precise purpose of the 'without prejudice' clause but presumably it is intended to indicate that any consent that is obtained may deal with matters as between the parties to the consent but cannot discharge either party of obligations that either may owe to others, or to the international community more generally. Finally, the clause stipulates that 'consent should be sought'. The clause does not use the mandatory 'shall' but the softer imperative 'should'; nor does the clause stipulate the consequences of failing to obtain the consent of all formation states and certainly does not use the formulation 'should be sought and obtained'.

Third, in addition to the consents that 'should be sought', sentence [C] calls upon the Contracting Party where the injection is occurring, to cooperate with: (1) other relevant Contracting Parties, (2) other States, and (3) other relevant entities. It is evident that this obligation is not confined to formation states (or presumably this sentence would have used the same terminology as the consent clause) although one would think, given the scope of the consent clause, that a reservoir State would always qualify as a relevant Contracting Party or 'other State'. It is not clear what the term 'other relevant entities' is designed to capture but presumably it might include global and regional treaty organizations such as the Protocol secretariat and conference of the parties, OSPAR, and, where relevant, a body like the EU. The cooperation is designed for two ends: (1) to ensure adequate sharing of information, and (2) to ensure that these Guidelines are implemented effectively. These objectives should be the measure of the information that must be shared which must also be 'in accordance with international law'. One could anticipate that an exchange that is adequate to ensure effective implementation of these Guidelines will need to be both detailed and extensive and indeed address all of the topics covered by the substantive requirements of the Guidelines. The clause provides some guidance as to the means of effecting cooperation insofar as it references 'arrangement or agreement' but clearly these are just possible modes of attaining the objective.

The Guidelines contain two other references to transboundary movement both in the section of the Guidelines dealing with the characterization of the sub-seabed geological formation. ${ }^{76}$ Thus, section 6.2 instructs that in selecting a site for geological storage of $\mathrm{CO}_{2}$ the geological assessment should take account of potential migration and leakage pathways over time (including 
transboundary movement) and potential effects to the marine environment of leakage of $\mathrm{CO}_{2}$. A second reference in the section largely follows part of the previously quoted and discussed section 1.10. ${ }^{77}$

While Dixon et al take the view that Guidelines under the Protocol are for guidance only, and not legally binding (unlike decisions adopted under OSPAR), these Guidelines offer the most detailed prescriptions for sub-seabed disposal of $\mathrm{CO}_{2}$ into shared geological formations. ${ }^{78}$ It is also possible that the Guidelines could attain additional normative weight through referential incorporation in other instruments which might, for example, require states to apply generally accepted standards or guidelines. ${ }^{79}$

\subsection{The Law Governing Seabed Operations in Areas of Overlapping Maritime Claims Pending Delimitation}

There are overlapping maritime claims in many areas of the world. These may include overlapping claims to a territorial sea, an EEZ and a continental shelf. Whereas Article 15 of U NCLOS establishes a default equidistance entitlement in the case of overlapping claims to a full $12 \mathrm{~nm}$ territorial sea, ${ }^{80}$ there is no default entitlement rule in the case of overlapping EEzs and continental shelves, only a duty to negotiate a delimitation by agreement with a view to reaching an equitable solution, failing which the Parties shall resort to dispute settlement under Part XV. ${ }^{81}$ Part XV (Article 298(1)(a)) permits a state to opt out of binding compulsory dispute settlement with respect to Articles 15, 74 and

\footnotetext{
$77 \quad$ Ibid s.6.5.

78 Dixon et al (n 12) at 436.

79 See generally Catherine Redgwell, 'Mind the Gap in the GAIRS: The Role of Other Instruments in LOSC Regime Implementation in the Offshore Energy Sector' in Nigel Bankes and Seline Trevisanut (eds), Energy from the Sea: An International Law Perspective on Ocean Energy, Brill Nijhoff (2014), and Angelica Bonfanti and Francesca Romanin Jacur, 'Energy from the Sea and the Protection of the Marine Environment: Treaty-Based Regimes and Ocean Corporate Social Responsibility' ibid. More specifically, UNCLOS (n 3) Article 208 requires coastal states to adopt laws and regulations to prevent, reduce and control pollution arising from sea-bed activities. Such domestic laws shall be 'no less effective than international rules, standards and recommended practices and procedures.'

8o UNCLOS ( $\mathrm{n}_{3}$ ) Article 15; absent agreement neither State is entitled to extend its territorial sea beyond the median line (subject to exceptions dealing with historic title or other special circumstances. See David Anderson and Youri van Logchem, 'Rights and obligations in areas of overlapping maritime claims' in Jayakumar et al (n 5o) pp. 121-228 at 196 \& 197 who observe that 'This rule is cast in unusual terms. It amounts to a restriction on the entitlement of each neighbouring State' and 'seeks to prevent overlapping claims to sovereignty by qualifying the entitlements of coastal States ... Hence, whilst ... the boundary remains disputed, and there are no special circumstances or historic titles, neither of the claimant States is 'prima facie' allowed to exercise sovereignty beyond the equidistance boundary line.' (reference omitted).

UNCLOS Articles 74(1) and 83(1).
} 
83 but in return such a party must accept the possibility of compulsory, but non-binding, conciliation. ${ }^{82}$ This section focuses on overlapping EEZ and continental shelf claims. Where the shelf and EEz have been delimited, the coastal state's rights are exclusive. Absent an agreed delimitation 'no such exclusivity can exist'.83

Articles 74 (EEZ) and 83 (continental shelf) impose procedural and substantive obligations on adjacent and opposite states pending agreement on delimitation. ${ }^{84}$ In particular, common paragraph three provides that: ${ }^{85}$

3. Pending agreement as provided for in paragraph 1, the States concerned, in a spirit of understanding and cooperation, shall make every effort to enter into provisional arrangements of a practical nature and, during this transitional period, not to jeopardize or hamper the reaching of the final agreement. Such arrangements shall be without prejudice to the final delimitation.

This provision does not limit de iure the powers of each State in a contested area ... these powers thus remain'. Provided that the claim is a reasonable one powers 'generally attributed to the coastal State by the relevant UNCLOS provisions' may be exercised but the paragraph does impose 'a double condition on the exercise of those rights. ${ }^{\prime 8}$

82 For a recent example of recent successful conciliation see Report and Recommendations of the Compulsory Conciliation Commission between Timor-Leste and Australia on the Timor Sea, 9 May 2018, Registry, Permanent Court of Arbitration. The Commission was able to assist the parties in negotiating the Treaty Between the Democratic Republic of Timor-Lese and Australia Establishing their Maritime Boundaries in the Timor Sea, New York, 6 March 2018. The treaty includes Annex B which is a joint development scheme for the Greater Sunrise field.

83 Anderson and van Logchem (n 80) at 198.

84 There is no similar provision in Article 15 .

85 The leading decision interpreting the scope of these obligations is Guyana v Suriname, Arbitral Award, 17 September 2007, esp. at paras 453-486 available at <http://www.pca -cpa.org/showpage5751.html?pag_id=1147>. Useful assessments of both the case and the language of Articles 74 and 83 of LOsC include Enrico Milano and Irini Papanicolopula, 'State Responsibility in Disputed Areas on Land and at Sea' (2011) 71 ZaöRV 587 esp at 6o6-621, Anderson \& van Logchem, (n 8o) and Davenport (n 50). On the background to articles 73 and 84 see Rainer Lagoni, 'Interim Measures Pending Maritime Delimitation Agreements' (1984), 78 AJIL 345. Most recently the British Institute of International and Comparative Law (n 1), has offered a comprehensive review of state practice under Articles 74(3) and 83(3) of UNCLOS.

86 Milano and Papanicolopulu (ibid) at 612. A reasonable claim is one that accords with the settled jurisprudence of the ICJ, ITLOS and Annex VII tribunals on maritime boundary delimitations and in particular the Black Sea Case; an unreasonable claim would be one that is manifestly unjustifiable when measured against that standard (id at 630). 
Rainer Lagoni has provided an authoritative account of the evolution of paragraph 3 of these two articles. ${ }^{87}$ Lagoni recalls that the paragraph represented a compromise and indeed a compilation of two different ideas that had been introduced in proposed language for this article. On the one hand, those states committed to the preeminence of the median or equidistance line favoured a formulation that prohibited a state from extending its shelf or EEZ (or in some proposals engaging in any exploration or exploitation activities beyond the equidistance line) absent an agreement between the states concerned. ${ }^{88}$ On the other hand, those states that favoured delimitation in accordance with equitable principles argued for a formulation that emphasized the importance of provisional arrangements. ${ }^{89}$ As can be observed, the final text incorporated elements of both of these ideas insofar as it refers to both the importance of making provisional arrangements as well as the commitment not to do anything that would jeopardize or hamper conclusion of an agreement, ${ }^{90}$ a point emphasized in the Award of the Arbitral Tribunal in Guyana $v$ Suriname. ${ }^{91}$ That Award also emphasized that the purpose of paragraph 3 is to permit utilization of disputed areas pending delimitation, thereby avoiding the suspension of economic development. ${ }^{92}$ The history of this paragraph fully justifies Lagoni's assertion that, at least at the time the paragraph was negotiated, it was 'in no way a codification of customary international law but represents an example of its progressive development. ${ }^{93}$

Paragraph 3 was subject to detailed analysis in the Award in Guyana $v$ Suriname and the Tribunal helpfully distinguished the two core and complementary obligations within the paragraph, first, the duty to use every effort to agree on provisional arrangements of a practical nature, and second, the duty not to hamper or jeopardise a final agreement. ${ }^{94}$

$87 \quad$ Lagoni (n 85).

88 Ibid at $35^{-}-351$.

89 Ibid.

9o Ibid at 349 , and see also at 353 the provision 'combines two basically different views ... attempts either to promote certain measures or to restrict others'.

91 (n 85).

92 Ibid at para. 460 .

93 Lagoni (n 85) at 354.

94 For further analysis of the decision see Milano and Papanicolopula (n 85) Anderson \& van Logchem (n 80) Davenport (n 5o) and BIICL (n 3). See also ITLOS, Dispute Concerning Delimitation of the Maritime Boundary between Ghana and Côte d'Ivoire in the Atlantic Ocean, Request for the prescription of provisional measures, Order 25 April 2015. For comment see Yoshifumi Tanaka, 'Unilateral Exploration and Exploitation of Natural Resources in Disputed Areas: A Note on the Ghana/Côte d'Ivoire Order of 25 April 2015 before the Special Chamber of ITLOS' (2015), 46 ODIL 315. See also Judgment, 23 September 2017, at paras 604-634. The Chamber (at para 604) emphasized the importance of the duty to negotiate in good faith especially 'where neighbouring States conduct maritime activities 


\subsubsection{Application to ccs Activities}

What then is the position in relation to proposed ccs related activities in an area of overlapping claims to the E EZ and continental shelf at least where both countries are parties to UNCLOS ${ }^{95}$ The main conclusion must be that the twin duties to make every good faith effort to enter into provisional arrangements and the duty not to take any actions that might jeopardize or hamper reaching a final agreement are just as applicable to ccs operations as they are to conventional oil and gas operations. The first branch would require a party proposing to authorize ccs evaluation activities in the disputed area to notify the other state(s) concerned, to provide relevant information, to seek cooperation and to commit to share any information obtained. Both parties should be flexible in their efforts to negotiate provisional arrangements. Such arrangements might include a joint development agreement or arrangement. The second branch would require the proposing state not to authorize drilling activities for any ccs related purposes such as for taking core samples from target formations to assess porosity, permeability and injectivity and for assessing the characteristics of sealing formations. Under the present state of the law, the proposing state cannot carry out these activities unilaterally but requires the agreement of the other state(s) concerned.

in close proximity.' The same would be true with respect to efforts to negotiate a 'provisional arrangement' but there could be breach of that duty (at para 628) absent a request for such an arrangement. Ultimately the Chamber found that Ghana was not in breach of either paragraph 3 but at least some of the Chamber's reasoning (at para 633) seems to turn on the specific and limited language of Côte d'Ivoire's request for relief.

As noted above, at the time of its adoption, paragraph 3 represented a progressive development of international law rather than its codification. It is still not clear whether both elements of paragraph 3 could be considered to be customary international law. Milano and Papanicolopulu (n 86) are not completely consistent on the point. Thus at 604 and 607 they suggest that while the duty not to hamper a final settlement might be grounded in the general principle to settle disputes peacefully and in good faith the same cannot be said of the positive duty to enter into arrangements of a practical nature. On the other hand, at 611, the authors suggest (without accompanying references or discussion) that paragraph 3 does reflect customary law. Anderson and van Logchem (n 80) at 208 seem content to conclude that this is 'a difficult question'. The BIICL Report (n 3 ) is equally cautious concluding (at para 401) that it is 'difficult to draw any general tends from the practice collated regarding the content of the obligations of Article 74(3) and 83(3) or any applicable customary international law obligations of restraint.' 

Agreements - Is There Space for ccs Operations?

Having examined the rules that apply where States (or at least those States that are party to UNCLOS) have not entered into a delimitation agreement, we can now examine how States might deal with storage operations in shared geological formation in their delimitation agreements. There is an extensive state practice and literature on this issue in the context of hydrocarbon deposits. ${ }^{96}$ The options ${ }^{97}$ for dealing with this issue include: (1) silence, (2) the inclusion of a basic straddling deposit or unity of deposit clause, and variations on such a clause, (3) so-called framework agreements, and (4) joint development agreements. The following sections examine each of these options with a view to determining the extent to which these arrangements address the use of shared geological formations for CCS operations or $\mathrm{CO}_{2} \mid$ EOR operations. ${ }^{98}$

\subsection{Silence}

The parties may elect to effect a delimitation without addressing the issue of shared geological formations at all. This gives rise to the question as to what the default rules would be in such a case, either with respect to petroleum operations or $\mathrm{CO}_{2}$ storage and disposal operations. It is fairly clear that Article 74 and 83 UNCLOS and, in particular, common paragraph 3 are no longer relevant - they are spent. The subject matter of the two articles is that of delimitation. Once the parties have made their delimitation agreement(s), those agreements assume priority - at least with respect to the issue of delimitation. ${ }^{99}$ Furthermore, paragraph 3 is certainly no longer applicable. After all,

96 See, for example, Ong (n 5o); Vasco Becker-Weinberg, Joint Development of Hydrocarbon Deposits in the Law of the Sea, Hamburg Studies on Maritime Affairs, vol. 30 (Springer, 2014); William T Onorato, 'Apportionment of an International Common Petroleum Deposit' (1977) 26 ICLQ 324-337, Rainer Lagoni, 'Oil and Gas Deposits Across National Frontiers' (1979) 73 AJIL 215-243 and Peter Cameron, 'The Rules of Engagement: Developing Cross-Border Petroleum Deposits in the North Sea and the Caribbean' (2006) 55 ICLQ 559-586.

97 I have applied this categorization previously in Nigel Bankes, 'Recent Framework Agreements for the Recognition and Development of Transboundary Hydrocarbon Resources' (2014), 19 International Journal of Marine and Coastal Law 666-69o and Nigel Bankes, 'The regime for transboundary hydrocarbon deposits in the maritime delimitation treaties and other related agreements of Arctic states" (2016) 47(2) Ocean Development and International Law 141-164.

98 See also UnfCcc, Transboundary cCs Technical paper (n 6) at para 110 noting that 'Existing agreements for the management and shared natural resources (e.g. on the use of the aquifer or reservoir) might apply even if they do not expressly contemplate ccs.'

See paragraph 4 of each Article. 
paragraph 3 commences with the words 'Pending agreement'. The agreement that is referenced here is the agreement on delimitation referred to in paragraph 1. Thus, the twin obligations of that paragraph no longer apply. One should recall in particular that the duty 'not to jeopardize or hamper' is a duty not to jeopardize or hamper the reaching of a final agreement. The delimitation agreement is that final agreement. Lagoni agrees remarking at the end of a section headed 'Application ratione temporis' that 'The obligation [to pursue good faith negotiations for a provisional agreement] ceases when the final delimitation agreement is reached. ${ }^{100}$

As a result, neither the two Articles, nor the interpretive case law, are directly applicable as treaty obligations post the conclusion of a delimitation agreement. However, the general duty to cooperate with respect to shared resources continues as does the parallel duty to cooperate as well as the general obligations under UNCLOS, as outlined above. ${ }^{101}$ In addition, a party to the PLDC will need to observe the relevant provisions of the Specific Guidelines to the extent that it is contemplating disposal operations in a shared geological structure. ${ }^{102}$

\subsection{The Basic Clause and Its Variants}

Agreements delimiting the continental shelf and $\backslash$ or the EEz frequently make provision for the discovery of hydrocarbon deposits that straddle the agreed delimitation line. An early and oft-cited example is the 1965 Agreement between the United Kingdom (UK) and Norway ${ }^{103}$ which provides that:

If any single geological petroleum structure or petroleum field, or any single geological structure or field of any other mineral deposit, including sand or gravel, extends across the dividing line and the part of such structure or field which is situated on one side of the dividing line is exploitable, wholly or in part, from the other side of the dividing line, the Contracting Parties shall, in consultation with the licensees, if any, seek to reach agreement as to the manner in which the structure or field

\footnotetext{
100 Lagoni, Interim Measures (n 85).

101 See also Eritrea v Yemen, Second Phase, December 17, 1999, <http://www.pca-cpa.org/ showpage.asp?pag_id=116o $>$ esp at paras $85^{-86}$. Reference might also be had to the general duty of good faith under both customary law and LOSC Article 300 as well as more general obligations of restraint based on the obligation not to take steps that would aggravate or extend a dispute. See BIICL Report (n 3) at paras 65-66 and also South China Sea Award, 12 July 2016, Registry, Permanent Court of Arbitration, at paras 1166-1173.

102 See section 3.2 above.

103 Agreement between the Government of the United Kingdom of Great Britain and Northern Ireland and the Government of the Kingdom of Norway relating to the delimitation of the continental shelf between the two countries, 10 March 1965, 551 UNTS 213, Article 3 .
} 
shall be most effectively exploited and the manner in which the proceeds deriving therefrom shall be apportioned.

In some cases the discovery of such straddling deposits and the resulting consultation has led to the conclusion of specific treaties elaborating on the rules for exploiting such a deposit, beginning with the Frigg Agreement in 1976.104 These rules are typically based on the concept of unitization (which involves treating the entire pool as a single ownership unit) ${ }^{105}$ with apportionment of costs and production based on the distribution of the underlying hydrocarbon reserves. ${ }^{106}$ Project operations are governed by the terms of unitization and operating agreements concluded between the licensees on either side of the line, typically subject to the agreement or approval of both governments. The unit operator is appointed by agreement between the licensees subject again to the approval of the governments. ${ }^{107}$

The question for present purposes is whether a clause such as that contained in the UK/Norway Agreement as well as the subsequent pool-specific development agreements should be read as extending to cCS operations and $\mathrm{CO}_{2} \mid$ EOR operations. It is perhaps easiest to begin with $\mathrm{CO}_{2} \mid$ EOR operations. These operations are strictly ancillary to the principal purpose of exploiting a hydrocarbon reservoir - they are designed to enhance production. It seems clear therefore that such operations would fall within the language of Article 3 of the Norway/UK Agreement. Such operations would also likely fall within

104 See Agreement relating to the exploitation of the Frigg Field Reservoirs and the transmission of gas therefrom to the United Kingdom (London, 10 May 1976) 1098 UnTs 3 . The Frigg Field was abandoned in 2004, see Norwegian Petroleum Directorate, $\mathrm{CO}_{2}$ Storage Atlas, Norwegian North Sea (2012) at 10, <http://www.npd.no/Global/Norsk/3-Publikasjoner/ Rapporter/PDF/CO2-ATLAS-lav.pdf $>$. Other reservoir-specific agreements include, Agreement relating to the exploitation of the Statfjord Field Reservoirs and the offtake of petroleum therefrom (Oslo, 16 October 1979) 1254 UNTS 379, Agreement relating to the exploitation of the Murchison Field Reservoir and the offtake of petroleum therefrom (Oslo, 16 October 1979) 1249 UNTS 173 and (between the UK and the Netherlands) the Agreement relating to the exploitation of the Markham Field Reservoirs and the offtake of petroleum therefrom (The Hague, 26 May 1992) 1731 UNTS 30235.

105 See Frigg Agreement, ibid, Article 1(1) 'The gas in the Frigg Field Reservoir and the hydrocarbons produced with or from the gas (excluding oil underlying the gas and gas and oil in other horizons), referred to in this Agreement as "Frigg Gas", shall be exploited as a single unit ....'

106 Ibid, Article 2(2): 'The two Governments shall consult with a view to agreeing a determination of the limits and estimated total reserves of the Frigg Field Reservoir and an apportionment of the reserves therein as between the Continental Shelf appertaining to the United Kingdom and the Continental Shelf appertaining to the Kingdom of Norway. For this purpose the licensees shall be required to submit to the Governments a proposal for such determinations.'

107 Ibid Article 5. 
the language of most pool-specific development agreements, ${ }^{108}$ although the institution of such operations would likely require the consent of the two governments under the terms of these specific treaties. ${ }^{109}$ Plans to commence $\mathrm{CO}_{2} \mid$ EOR operations may also lead to a restatement of recoverable reserves; however, all of these pool-specific development agreements provide for this eventuality and therefore would apply whether a request for a restatement is triggered by additional drilling which causes the licensees of the governments to revise their understanding of the parameters of the pool, or whether it is triggered by the introduction of EOR operations. ${ }^{110}$

But what is the position with respect to a shared saline formation? What is the position where a project in a conventional hydrocarbon reservoir moves from a $\mathrm{CO}_{2} \mid \mathrm{EOR}$ operation to a pure disposal operation? And what is the position where a straddling reservoir has been abandoned and is now being considered for ccs purposes (the Frigg Gas field is a case in point). ${ }^{111}$ The Norway $\backslash$ UK version of the straddling deposit clause addresses two subjects: (1) geological petroleum structures and petroleum fields; and, (2) single geological structures or fields for any other mineral deposit, including sand or gravel. Furthermore, the clause is concerned with the exploitation of these resources for commercial gain and presumably by means of extraction rather than exploitation by injection. There may be arguments both ways as to whether such clauses can be read as embracing the operations referred to above i.e. exploitation by injection of a saline reservoir, cross-over operations from EOR to pure disposal, and the use of abandoned petroleum reservoirs. Perhaps the arguments are strongest in relation to the use of abandoned petroleum reservoirs since CCS can be seen as the continued exploitation of such a reservoir. The arguments may be weaker with respect to a shared saline aquifer since it

108 I say 'most' because the Frigg Agreement, Article 1(1) only applies to 'Frigg Gas' and specifically does not apply to 'oil underlying the gas'.

109 See, e.g. Frigg Agreement (n 104), Article 4(1) calling for government approval of a proposed scheme for the conservation of gas; Article 11 of each of the Murchison and Statjford Agreements refers to the need for government approval of amendments to the exploitation programme which programme should have as its objective the exploitation of the reservoir 'in such a manner as to prevent the waste of petroleum and minimizes losses of reservoir energy' $\mathrm{A} \mathrm{CO}_{2}$ \EOR recovery programme would fall within this objective.

110 Frigg Agreement (n 104) Article 3.

111 See Norway's North Sea Storage Atlas, (n 104) at 59-6o which evaluates both a pure disposal operation and an enhanced gas recovery operation in the abandoned Frigg field. The operation would take advantage of 'a huge [saline] aquifer that is connected to the field'. The Report acknowledges that a prerequisite for any injection operation would be integrity studies of abandoned wells that penetrate the formation. 
may be more difficult to describe such a structure as a 'geological structure or field of any other [i.e. non-petroleum] mineral deposit' (emphasis added).

The UK\Norway Agreement offers a relatively simple form of a straddling deposit clause. While delimitation agreements continue to be concluded with this type of clause, other agreements contain more sophisticated versions which might address such matters as the exchange of drilling information and perhaps dispute settlement. ${ }^{112}$ In general, it seems fair to say that the more detailed the clause the more likely that it can be interpreted as referring only to hydrocarbon reservoirs and the exploitation of hydrocarbons. However, other forms of the clause use more general language that does not refer to hydrocarbon resources or petroleum reservoirs. For example, the FrancelSpain delimitation agreement of 1974 (which also creates a joint development zone (JDZ)) refers to the exploitation of a deposit of a natural resource. ${ }^{113}$ It does not seem unreasonable to think that injection of $\mathrm{CO}_{2}$ into a shared saline aquifer might qualify as the exploitation of that shared resource. But equally, other similar clauses are explicitly confined to petroleum and $\backslash$ or natural gas ${ }^{114}$ or to the exploitation of deposits of mineral resources ${ }^{115}$ and would therefore likely not apply to operations in saline aquifers.

112 See for example Article 2 of the Agreement between the Government of the Kingdom of Denmark together with the Home Government of the Faroe Islands and the Government of the United Kingdom of Great Britain and Northern Ireland relating to the Maritime Delimitation in the area between the Faroe Islands and the United Kingdom, Torshavn, 18 May 1999, 4 І м в 2956. Ім в refers to the series International Maritime Boundaries (various editors, 1993 - date).

1132 Імв 1727. See also Agreement between Italy and Spain Relating to the Delimitation of the Continental Shelf between the Two Countries, 19 February 1974, 2 IM B 1601, Article 2 applies to a 'deposit of natural resources'.

114 Agreement between the Governments of Malaysia and Indonesia on the Delimitation of the Continental Shelves between the Two Countries, 27, October 1969, 1 Iм 1019, Article 4; Maritime Delimitation Treaty between Columbia and Honduras, 2 August 1986, 1 I 1 в 503, Article 3, 'hydrocarbons or natural gas deposits or fields'; Agreement between the Government of the Kingdom of the Netherlands and the Government of the United Kingdom of Great Britain and Northern Ireland relating to the exploitation of single geological structures extending across the dividing line on the continental shelf under the North Sea, 6 October 1965, Cmd 3254, Article 1, 'geological mineral oil or natural gas field or structure' (this agreement is unusual since it was a stand-alone agreement dealing with straddling deposits and executed contemporaneously with a separate delimitation agreement).

115 Estonia \Russia (2005), 6 Iм в 4582, Article 4; Trinidad and Tobago \Grenada (2010), 7 IM B 4705 , Article viI straddling 'oil and gas structure or field or any other mineral deposit'; Venezuela|Netherlands (Antilles) (1978), 1 Iм в 615, Article 6 'a single geological structure or mineral field containing oil or natural gas'; 
As for the field-specific unit operations agreements referred to above, it seems fairly clear that such agreements would not apply to either $\mathrm{CO}_{2} \mid \mathrm{EOR}$ operations crossing over to pure disposal or to storage and disposal operations in an abandoned field (the Frigg situation). While such agreements may not terminate automatically with the cessation of production and abandonment, ${ }^{116}$ it seems clear that all these agreements are concerned with production of petroleum and not with pure $\mathrm{CO}_{2}$ disposal operations and are therefore inapplicable.

In sum, the general conclusion is that while delimitation agreements that deal with straddling deposits as well as subsequent field-specific agreements will likely also cover $\mathrm{CO}_{2} \backslash$ EOR operations, it is much more difficult to conclude that such agreements were intended to address the use of shared saline aquifers for $\mathrm{CO}_{2}$ disposal purposes. More specific drafting directed at the used of shared geological structures for storage or disposal purposes would be more appropriate. A simple version of such clause might be as follows:

If any geological structure that has the potential to be used for geological storage or disposal purposes extends across the dividing line, and the part of such structure or field situated on one side of the dividing line is exploitable, wholly or in part, from the other side of the dividing line, the Contracting Parties shall, in consultation with the licensees, if any, seek to reach agreement as to the exploitation of that structure for storage or disposal purposes.

In addition, and in light of the discussion above of the London Protocol's Sub-Seabed Geological Formations Guidelines (2012), contracting parties to the Protocol might wish to add further text such as the following: 'Any such agreement should take account of any guidelines for the assessment of geological formations for storage or disposal purposes developed by any relevant international organization.' The suggested language would be broad enough to embrace not only the work within the London Protocol but also any future work within OSPAR or perhaps work by the IPCC.

\subsection{Framework Agreements}

Framework agreements dealing with shared hydrocarbon resources are bilateral agreements which aim to provide a detailed framework for the treatment of straddling petroleum deposits thereby obviating the need to negotiate field

116 The agreements provide for amendments or termination by agreement at any time: Frigg Agreement, (n 104) Article 31; Statfjord (n 104), Article 24, Murchison (n 104), Article 24. 
specific treaties. ${ }^{117}$ While most such agreements are free-standing agreements (e.g. the UK $\backslash$ Norway Framework Agreement), in some cases the framework provisions may be included in or appended to a delimitation agreement. Such is the case, for example, with the Norway $\backslash$ Russia Barents Sea Treaty. While specific answers to the above questions will of necessity turn on their precise language, these agreements generally apply only to 'petroleum activities' or some such similar term ${ }^{118}$ or to hydrocarbon deposits. ${ }^{119}$ It follows from this that while such agreements will therefore cover $\mathrm{CO}_{2} \mid$ EOR operations ${ }^{120}$ they will not cover cross-over operations, saline aquifer disposal activities or disposal activities into abandoned reservoirs, except perhaps where the $\mathrm{CO}_{2}$ is

117 The agreements include (1) Framework Agreement between the United Kingdom and Norway concerning Cross-Boundary Petroleum Co-operation, 4 April 2005, 7 IMB 5214, Report No. 9-15(6), (2) Agreement between Canada and the French Republic Relating to the Exploration and Exploitation of Transboundary Hydrocarbon Fields, 17 May 2005, unpublished, on file with the author, (the agreement has been ratified by France but not by Canada), (3) Framework Treaty relating to the unitization of hydrocarbon reservoirs that extend across the delimitation line between the Republic of Trinidad and Tobago and the Bolivarian Republic of Venezuela, 20 March 2007, 7 І І B 4649, Report No. 2-13(4), (4) Agreement between Iceland and Norway concerning transboundary hydrocarbon deposits, 3 November 2008, 7 Iм 5123 , Report No. 5123, (5) Treaty between Norway and the Russian Federation concerning Maritime Delimitation and Cooperation in the Barents Sea and Arctic Ocean, 15 September 2010, 7 IMB 5167 and its attached Annex II dealing with Transboundary Hydrocarbon Deposits, Report No. 9-6(3), (6) Framework Agreement between the Republic of Cyprus and the Arab Republic of Egypt Concerning the Development of Cross-Median Line Hydrocarbon Resources, 21 January 2012 available on FAOLEx here http://faolex.fao.org/docs/pdf/bi-110369.pdf and (7) Agreement between the United States and the United Mexican States Concerning Transboundary Hydrocarbon Reservoirs in the Gulf of Mexico, 20 February 2012, 7 IM B 4613, Report No. 1-5(3). For discussion of some of these agreements see Cameron (n 96) and Bankes (n 97).

118 Article 1.1 of the UK|Norway Framework Agreement stipulates that the Agreement applies to cross-boundary cooperation between the two states with respect to petroleum activities. While the scope is arguably broader (since the substantive provisions also cover cross-boundary projects) other provisions make it clear that the agreement is confined to oil and gas activities and not disposal projects. Thus cross-boundary projects are defined in terms of transboundary petroleum reservoirs, pipelines and associated facilities. The Iceland $\backslash$ Norway Agreement refers only to the exploitation of transboundary hydrocarbon deposits; similarly the Canada|France Agreement is clearly confined to transboundary hydrocarbon fields and activities.

119 Norway $\mid$ Russia, Article 5 and Annex II; Iceland $\backslash$ Norway; Cyprus $\mid$ Egypt, Article 1, scope.

120 The UK|Norway Framework Agreement makes this clear insofar as it defines (Article 1.2) 'exploitation' as including injection, reinjection or storage of any substance used for or derived from the appraisal, production, treatment and processing of gas or liquids from a reservoir. 
derived from the processing of produced substances (as is the case for example with the Norwegian Sleipner and Snøhvit projects). ${ }^{121}$

In sum, such framework agreements would require comprehensive redrafting to include pure CCs disposal operations. Alternatively, parties could negotiate a parallel framework agreement expressly addressing ccs operations in the full range of shared geological structures.

\subsection{Joint Development Agreements}

The literature refers to two main types of joint development agreements (JDAs). ${ }^{122}$ The first category comprises JDAs which are put in place pending agreement on delimitation (provisional arrangements ${ }^{123}$ ) whereas the second category of JDA may be created as part of a delimitation agreement and is intended to be permanent. The distinction between these categories of agreement is likely of little significance for present purposes, since, as with the above arrangements, the question that concerns us is whether these agreements, whether temporary or permanent, whether associated with an agreement on delimitation or not, are intended to, or can be read to apply to, CCS related activities as well as petroleum activities. ${ }^{124}$

121 This exception follows from the definition of exploitation quoted, $i d$. There is no doubt room to argue that the reinjection activities covered by the agreement are limited to injection in to hydrocarbon formations. The One North Sea Report (n 20) does however suggest (at 86) that the ideas underlying the Framework Agreement might inform a potential parallel agreement dealing with ccs.

122 See Masahiro Miyoshi, "The Joint Development of Offshore Oil and Gas in Relation to Maritime Boundary Delimitation' (1999), 2(5) Maritime Briefing 1-51.

123 UNCLOS (n 3 ) Articles 74(3) \& 83(3) and see discussion above in section 3.3.

124 The JDAs examined for the purposes of this chapter are as follows: (1) Agreement between the Government of Bahrain and the Kingdom of Saudi Arabia, 22 February 1958, 2 Ім в 1489, Report No. 7-3; (2) Convention between France and Spain Concerning on the Delimitation of the Continental Shelf in the Bay of Biscay, 29 January 1974, IMB 1719, Report No. 9-2; (3) Agreement between Japan and the Republic of Korea Concerning the Establishment of Boundary in the Northern Part of the Continental Shelf Adjacent to the Two Countries, 30 January 1974, 1 I M B 1057, Report No. 5-15; (4) Norway/Iceland (Jan Mayen) (1980) 2 Імв 1755; (5) Memorandum of Understanding between Malaysia and the Kingdom of Thailand on the Establishment of a Joint Authority for the Exploitation of the Resources of the Sea-Bed in a defined Area of the Continental Shelf of the Two Countries in the Gulf of Thailand, 13 May 1990, 1 Імв 1099, Report No. 5-13(2); (6) Memorandum of Understanding between Malaysia and the Socialist Republic of Vietnam for the Exploration and Exploitation of Petroleum in a Defined Area of the Continental Shelf involving the Two Countries, 5 June 1992, 3 гмв 2335, Report No. 5-19; (7) Maritime Delimitation Treaty between Jamaica and the Republic of Colombia, 12 January 1993, 3 Iм в 2179, Report No. 2-1, (8) Agreement between the Republic of Kazakhstan and the Russian Federation on Demarcation of the Seabed in the Northern Caspian Sea for the Purpose of Exercising Sovereign Rights to the Use of Subsoil 
While some of these agreements are expressly confined to petroleum or mineral extraction activities ${ }^{125}$ most are broader in their application. For example, the JDZ established by the France|Spain agreement of 1974 refers more generally to the prospecting for, and exploitation of, the resources of the $\mathrm{JDZ}^{126}$ while the 1979 Agreement between Malaysia and Thailand refers generally to the 'exploration and exploitation of the non-living natural resources

Resources, 6 July 1998, and the Protocol, 13 May 2002, 5 Імв 4013, Report No. 11-1; (9) Memorandum of Understanding between the Royal Government of Cambodia and the Royal Thai Government regarding the Area of their Overlapping Maritime Claims to the Continental Shelf, 18 June 2001, 5 Ім в 3735, Report No. 5-24, (an agreement to establish a joint development treaty); (10) Treaty between the Federal Republic of Nigeria and the Democratic Republic of Săo Tomé and Príncipe on the Joint Development of Petroleum and other Resources in Respect of Areas of the Exclusive Economic Zone of the Two States, 21 February 2001, 5 Ім 3 3638, Report No. 4-10; (11) Australia|Timor-Leste (2003), 5 Ім в 3806, Report No. 6-2o (1) \& (2); (12) Treaty Between the Republic of Guyana and the State of Barbados Concerning the Exercise of Jurisdiction in their Exclusive Economic Zones in the Area of Bilateral Overlap within each of their Outer Limits and beyond the Outer Limits of the Exclusive Economic Zone of Other States, 2 December 20035 Iм в 3578, Report No. 2-27; (13) Agreement on the Exploration and Production of Hydrocarbons in the Common Interest Maritime Zone between the Democratic Republic of the Congo and the Government of the Republic of Angola, 30 July 2007, 6 Iмв 4270, Report No. 4-15, and Protocol of Agreement... Approving Offshore Unitization Prospects, 10 September 2001, 6 Ім в 4281, Report No. 4-16; (14) Mauritius|Seychelles, (2012) 6 Ім в 4391. Mention might also be made to the Denmark $\mid$ Faroes and UK agreement (n 112) This Agreement establishes a Special Area rather than a joint development zone. The Special Area is principally an area of shared rights and responsibilities with respect to fisheries matters but the Agreement also contemplates that special provisions should also apply to oil and gas operators working within the Special Area. Arguably these provisions and restrictions would also apply to ccs related operations. Finally, the chapter does not take account of the most recent Timor-Leste Australia (and its annex dealing with the Great Sunrise project) resulting from the compulsory conciliation proceedings initiated by Timor-Leste (n 82).

125 The Japan|Korea agreement applies to natural resources which is defined as petroleum and other resources produced in association with petroleum; the Malaysia|Vietnam JDZ applies to the exploration and exploitation of petroleum; the Congo\Angola agreement creates a 'common interest maritime petroleum zone"; the Australia|Timor-Leste agreement applies to the petroleum resources of the Joint Petroleum Development Area and the Norway\Iceland (Jan Mayen Agreement) applies to "co-operation [within the JDZ] ... in connection with the exploration for and exploitation of hydrocarbon resources .... Finally, while some of the language of the Protocol to the Kazakhstan $\backslash$ Russia Agreement refers more generally to economic activity in relation to straddling geological structures these provisions should likely be interpreted in light of the dominant concern of the agreement which is clearly the hydrocarbon resources of the Northern Caspian Sea.

126 France|Spain Agreement, Annex II. Paragraph 2 of the Annex refers to mining regulations but many jurisdictions licence ccs activities through the mineral or petroleum legislation. Other provisions in the Annex such as paragraph 7 which refers to products obtained from the JDZ may suggest a narrower interpretation that does not admit of the 
of the sea-bed and subsoil' of the overlapping area of claims. ${ }^{127}$ The treaty between Barbados and Guyana similarly applies to the jurisdiction, control, management, development, exploration and exploitation of living and nonliving resources, as well as all other rights and duties established in the [Law of the Sea] Convention' within the Co-operation Zone. ${ }^{28}$ The JDZ treaty between Nigeria and Sao Tome and Principe is also far-reaching. ${ }^{129}$ This agreement applies to 'development activities' within the zone. ${ }^{130}$ Such activities are defined as 'any economic activity in or concerning the Zone, including petroleum activity, fishing activity, all other activities for the development or exploitation of other mineral or living resources of the Zone and all forms of exploration and research related to any of the foregoing.' Furthermore, Article 32 provides that the Zone Plan (to be developed by the Joint Authority) may make provision for non-petroleum development activities within the Zone. Equally notable is the 2012 treaty between Mauritius and the Seychelles establishing the extended continental shelf beyond the respective EEzs of the two countries as a joint management area. ${ }^{131}$ Within that area, the Contracting Parties, through a Designated Authority, 'shall jointly control, manage and facilitate the exploration of the continental shelf ... and the conservation, development and exploitation of its natural resources'.132

It follows from the above that while all of these agreements would cover $\mathrm{CO}_{2} \mid$ EOR operations many of these agreements are also broad enough to cover cross-over operations from $\mathrm{CO}_{2} \mid \mathrm{EOR}$ to pure disposal operations in depleted reservoirs, disposal operations in a previously abandoned reservoir ${ }^{133}$ as well as to pure disposal operations in a saline aquifer. This would no doubt

application of the provisions to disposal activities but the general tenor of the treaty and the annex does admit of a broader application.

127 Malaysia|Thailand, MoU, Annex I, Article III. Furthermore Annex III (which establishes the joint authority) provides that the purpose of the joint authority 'exploration and exploitation of the non-living natural resources of the sea-bed and subsoil, in particular petroleum' which of course makes it crystal clear that the parties were contemplating the exploitation of other resources within the JDZ. See also the Guinea-Bissau|Senegal JDZ Agreement and accompanying Protocol of Agreement establishing a joint Agency and other institutions. These arrangements apply to fisheries and petroleum resources but also refers to other resources of the Zone.

128 Barbados $\backslash$ Guyana, Article 1.

129 Nigeria|Sao Tome and Principe (2001).

130 Ibid, Article 3.

131 Mauritius|Seychelles.

132 Ibid, Article 3.

133 See however Congo $\backslash$ Angola Agreement and the accompanying Protocol (which are concerned solely with a 'common interest maritime petroleum zone'). Article 10 of the Agreement contemplates that it will expire "upon completion of abandonment work of the installations of the final reservoir under exploitation. Article 16 of the annexed 
require the joint authority (where provided for) to develop specific rules in relation to this activity.

\section{$5 \quad$ Other Possible Arrangements}

The analysis above shows that while delimitation treaties between adjacent and opposite states will frequently deal with the possibility of shared petroleum deposits they do not deal expressly with the use of shared geological structures for the purposes of $\mathrm{CO}_{2}$ disposal or storage. While such agreements may certainly in some cases be read to include $\mathrm{CO}_{2} \mid$ EOR operations, it would be very difficult to read them as addressing other forms of cCs operations. Many JDAs are framed more broadly and thus might embrace ccs saline operations but that hardly addresses the question of whether they are really fit for the purpose. Accordingly, this last section canvasses the limited literature discussing what a bespoke agreement for cCs operations in a shared geological structure might look like.

The International Energy Agency has developed a Model Regulatory Framework for cCS activities. ${ }^{134}$ While the principal purpose of the document is to provide advice on the design of a domestic regulatory framework, the Model also acknowledges the need to take account of a number of transboundary issues. These include not only export and transit issues but also the issues addressed in this chapter which the report lists as: ${ }^{135}$

- Unintended migration or leakage of injected $\mathrm{CO}_{2}$ in the sub-surface across jurisdictional borders;

- Use of storage complexes that span jurisdictional borders;

- Secondary effects from storage activities occurring across jurisdictional borders (e.g. due to a sub-surface pressure front or displacement of sub-surface fluids across borders).

In response to these issues, the report identifies the need for regulatory coordination and harmonization and either the selection of a single competent authority for a cCs project or 'joint regulatory responsibility'. ${ }^{136}$ Harmonization and coordination might extend to such things as coordinated bidding rounds for storage exploration and efforts to optimize the use of pipeline and other

unitization protocol contemplates that it will remain in force 'as long as the production period in the Unitization zone lasts'.

134 International Energy Agency, Carbon Capture and Storage: model regulatory framework, 2010. <https://www.iea.org/publications/freepublications/publication/model_frame work.pdf>

135 Ibid at 30 .

136 Ibid at 31 . 
infrastructure; application of market rules for access to storage; and agreement on liability and GHG accounting rules. ${ }^{137}$

In sum, the Model Framework provides some useful ideas but it is far from a systematic account as to the contents of either a state-to-state agreement or an operating agreement as between the private parties who might actually be charged with the responsibility for a cCs project.

Much the same can be said of the Technical paper prepared by the UNFCCC Secretariat in response to a request from the Subsidiary Body for Scientific and Technical Advice (SBSTA) in connection with qualifying CCS projects as CDM eligible. ${ }^{138}$ That paper also recommends drawing upon our experiences with water (including aquifers) and petroleum resources ${ }^{139}$ and briefly canvasses a broad range of relevant agreements. It notes that cooperation agreements in oil and gas already include common principles providing for inter alia: exchange of information; effective exploitation; equitable sharing of the resources; the protection of the environment including sometimes in joint management structures; appointment of contractors and operators; financial provision; and dispute resolution. ${ }^{140}$ The report also notes that JDAs are frequently more integrated and institutionally richer than other bilateral arrangements. ${ }^{141}$ The submissions to the Secretariat also emphasized that some guidance might be found in Decision 10/CMP.7 (and its Annex and Appendices), as to the topics that might be addressed in any bilateral agreement. ${ }^{142}$

Another source from which parties might draw are the unitization agreements typically used in the oil and gas industry to deal with production from straddling deposits of hydrocarbons. ${ }^{143}$ Unitization will typically be achieved by agreement between those commercial parties who have an interest as a licensee (i.e. as a working interest owner) from either government to a

137 id at 31 \& 32 . The starting point for developing appropriate $\mathrm{GH}$ G accounting rules will be the default rules developed by the IPCC in its 2006 IPCC Guidelines for National Greenhouse Gas Inventories, available <https://www.ipcc-nggip.iges.or.jp/public/2006gl/> .

138 UnfCCC, Transboundary ccs Technical paper (n 6 and related text).

139 Ibid at para 66.

140 Ibid at para 70.

141 Ibid at para 158.

142 This is the decision of the meeting of the parties to the Kyoto Protocol accepting CCS project as eligible within the CDM. FCCC/SBSTA/2012/MISC.12 and Add.1 (submissions from Australia and Cyprus on behalf of the EU).

143 Jacqueline Lang Weaver and David F Asmus, 'Unitizing oil and gas fields around the world: a comparative analysis of national laws and private contracts' (2006), 28 Houston Journal of International Law 1-190; Ana E Bastida et al, 'Cross-Border Unitization and Joint Development Agreements: An International Law Perspective' (2007) 29 Houston Journal of International Law 355. See also the One North Sea Report (n 20) at 86, suggesting that relevant principles and ideas could be drawn from the UK|Norway Framework Agreement (n 117). 
geographical area that forms part of the deposit. The unitization agreement will provide for the apportionment of production and expenses in accordance with the best scientific understanding as to the distribution of reserves underlying either side of the boundary and each of the different licence areas (or tracts). Thus each tract will be assigned a tract participation factor. The agreement will also make provision for future operations. ${ }^{144}$ Unitization agreements are only necessary where there are multiple tracts and multiple parties. If there is a single tract, or if there is a single owner of the different tracts that form the reservoir (or storage unit), then unitization is arguably unnecessary. This would be an unusual scenario in an oil and gas context which is an industry which thrives on competition ${ }^{145}$ but is perhaps a more likely scenario in a disposal context since operations are likely to be less competitive and more coordinated from the outset. Indeed, one of the goals of regulatory coordination between national authorities should likely be to try and ensure unified ownership of a target storage $\backslash$ disposal complex through coordinated offerings of storage acreage.

\section{Conclusions}

This chapter began with discussion of the storage part of the ccs chain considering $\mathrm{CO}_{2} \mid$ EOR operations as well as storage in a saline formation. A key conclusion is that injection in saline formations will likely affect a larger geographical area than injection in a depleted reservoir and that the effects of injection will include a pressure front in addition to the physical $\mathrm{CO}_{2}$ plume.

Section 3 examined general rules pertaining to the duty to cooperate with respect to shared resources as well as work conducted under the auspices of the Protocol to the London Dumping Convention to develop a set of Guidelines for the Assessment of Carbon Dioxide for Disposal into Sub-seabed Geological Formations including one key provision dealing with cases where there is the potential for the transboundary movement of injected $\mathrm{CO}_{2}$. A crucial point to

144 There may be one agreement dealing with unitization (the unitization agreement) and another agreement dealing with how to make decisions about subsequent operations (the unit operating agreement) or the two may be rolled together as a 'Unitization and Unit Operating Agreement'. The agreements will typically be confidential but standard forms are available and see also Weaver and Asmus, ibid, especially the Appendix commencing at 99 and containing sample clause from both unitization agreements and relevant domestic laws. One commonly used form is AIPN's (Association of International Petroleum Negotiators) 2006 Unitization and Unit Operating Agreement available on AIPN's website at <http://www.aipn.org/>.

145 Terence Daintith, Finders Keepers? How the Law of Capture Shaped the World Oil Industry, (Resources for the Future, 2010). 
emphasise is that the Guidelines suggest that injection should only proceed in such a case where consent has been sought from all countries with jurisdiction over such a storage formation. Section 3 also examined the implications of Articles 74(3) and 83(3) UNCLOS for the situation in which one party may be proposing to engage in cCs operations in an area of overlapping maritime entitlements and in the absence of an agreed delimitation. The analysis suggested that any storage operations in the area of overlapping entitlements, including any evaluation operations that required drilling operations, could only be carried out with the consent of all parties with an overlapping entitlement. Unilateral operations would be a breach of the obligations of restraint under Articles 74(3) and 83(3). It would also seem to follow that injection operations conducted outside the area of overlapping entitlement which might affect that area (either the physical plume or the pressure front) would also be unlawful insofar as such effects might prejudice the sovereign rights of the other party (depending on the outcome of any agreement or decision on entitlement).

Section 4 examined existing boundary delimitation agreements and joint development agreements to see to what extent they may be read as being applicable to CCS and $\mathrm{CO}_{2} \mid$ EOR operations. The general conclusion is that most delimitation agreements, even those with straddling deposit clauses likely do not extend to cover cCS saline operations; however most if not all would cover $\mathrm{CO}_{2} \mid$ EOR operations on the basis that such operations are incidental to petroleum recovery. It should also be noted that such operations would likely only be conducted where there was already in place a treaty-based unitization arrangement with respect to the field and that that treaty might well address the introduction of EOR operations either directly or indirectly (by triggering a re-assessment of recoverable reserves). While some JDAs only address petroleum operations, others are broadly framed. Such agreements would certainly cover $\mathrm{CO}_{2} \mid$ EOR operations but some may be read more broadly to cover CCS operations in a saline formation. Whether they are fit for purpose however is another question.

Section 5 considered other possible arrangements for ccs operations in storage complexes that cross a maritime boundary. While some work has been done on this topic both in the context of the PLDC and the Kyoto Protocol (CCS eligibility under the CDM), this work falls far short of a model bilateral (or broader) treaty arrangement. Finally, while there is some suggestion that oil and gas unitization agreements might provide a good model for such projects, this claim may be doubted insofar as such arrangements are designed to deal with the situation of multiple owners and multiple tracts. Such situations are common in an oil and gas context but in the case of storage operations, neighbouring states should take a more coordinated approach from the outset with a view to avoiding the situation of multiple owners. 